\title{
Global Ocean Markets
}

\author{
John Westwood, Barney Parsons and Will Rowley \\ Douglas-Westwood Associates . Canterbury United Kingdom
}

\section{Introduction}

It is only in recent times that nations have begun to recognize the size, diversity and complexity of the ocean industries and their importance to all. To many people marine equals shipping, which is indeed an important industry as the world fleet carries over $90 \%$ of the world trade by tonnage and shipbuilding is a business worth over U.S. \$32 billion per annum. Offshore oil \& gas is the world's biggest marine industry where oil production alone can have a value of more than $\$ 300$ billion per annum. Submarine cables are now a huge business that provides the "worldwide" part of the world wide web and enables the very existence of the internet.

But beyond the mega-businesses, the ocean industries are very wide-ranging from marine aquaculture to tourism, to education and research, and in total they contribute a considerable amount to global economic activity. And as research is constantly opening opportunities for new industries, from marine biotechnology to the extraction of gas hydrates, many would say we are only just at the beginning.

Our work on global markets is based on data gathered from many sources. Wherever possible we have used official statistics, but in many instances these are not available so we have developed estimates using other sources.

This paper takes a businessman's view of the ocean industries. It considers the major factors impacting them then gives examples of specific sectors. It discusses the range and value and recent developments using the

This paper takes a businessman's view of the ocean industries. results of major new studies completed by the authors. One major source was a study commissioned by the UK's Foresight Marine Panel from DouglasWestwood Associates and we are grateful for their permission for us to use extracts.

\section{The Global Market}

Most of the markets we discuss typically include three elements: the bought-in equipment, the cost of

\begin{tabular}{|c|c|}
\hline \multicolumn{2}{|l|}{ Table 1} \\
\hline Sector & U.S. $\$ B n$ \\
\hline offshore oil \& gas production & 300 \\
\hline oil \& gas expenditure & 86 \\
\hline shipping revenues & 234 \\
\hline naval expenditure & 225 \\
\hline submarine telecoms revenues & 69 \\
\hline leisure boating revenues & 38 \\
\hline shipbuilding & 32 \\
\hline aquaculture production & 22 \\
\hline$R \& D$ & 19 \\
\hline port development & 19 \\
\hline cruise industry & 18 \\
\hline marine services & 17 \\
\hline marine equipment & 15 \\
\hline port management & 13 \\
\hline leisure boats & 10 \\
\hline ship repair & 8 \\
\hline submarine cables & 8 \\
\hline education \& training & 3 \\
\hline desalination & 2 \\
\hline ocean survey & 1 \\
\hline minerals & 1 \\
\hline UUVs & 1 \\
\hline marine IT & 1 \\
\hline marine biotechnology & 1 \\
\hline
\end{tabular}

operations, and the output value. In short, the subject is complex.

This complexity is further increased by the fact that sectors overlap and one may supply to another-for example the shipbuilding industry supplies vessels to the offshore oil industry - therefore the values in Table 1 cannot be added together. However, the summation 
Figure 1. Geographic segmentation of the $\$ 747 \mathrm{Bn}$ global marine market

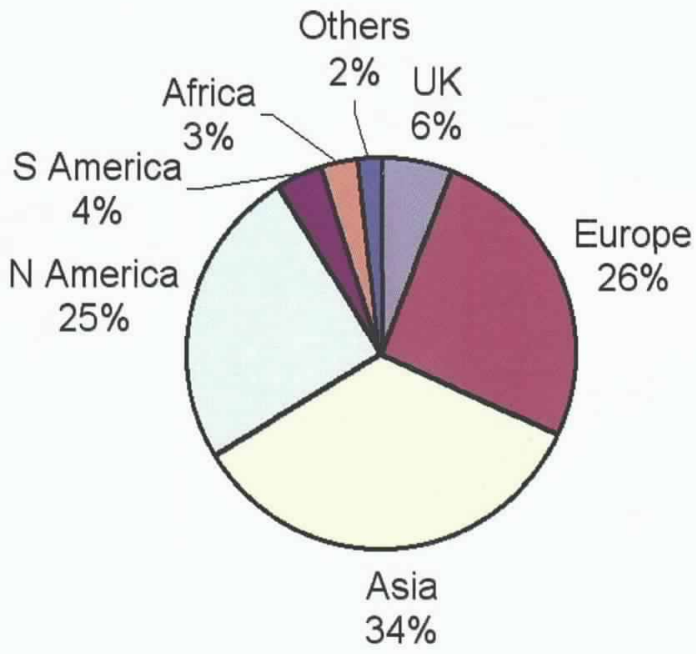

of the items that are expenditure, gives a value of $\$ 747$ billion and enables us to derive a view of the global segmentation of the marine industries. (Figure 1).

Global markets consist of three major regions; Europe and North America are similar in size forming $25 \%$ and $26 \%$ of the market. Asia forms the largest region at an estimated $34 \%$, with much of this shipbuilding and shipping activity centered in S.E. Asia.

However, it is important to recognize that while the data relate to the location of expenditure, decisions are often made in other regions. For example, global shipbuilding is centered in S.E. Asia, but many decision-making owners are in UK/Europe. Although offshore oil activity is global, decision-making is often in Europe and the U.S.

\section{Factors Impacting on the Marine Markets}

The major factor impacting on the marine industry is the level of global economic activity and the resultant amount of world trade. It is estimated that over $90 \%$ of world trade is carried by sea and over the period 1985 to 1999, world seaborne trade increased by $50 \%$ to about 5 billion tons with the largest increase coming in crude oil and oil products shipments. During 1990-98 growth averaged 3.2\% per annum. It is reported that in 1998 trade experienced its first dip for 15 years, which was due to the S.E. Asian economic problems. However, the decline was generally only within the region. Since then some of the countries concerned have accomplished a turnaround.

Cargo vessels continue to increase in size. Over the past 20 years, Lloyds Register data shows that the world fleet (of vessels of 100 gross tons [gt] or more) has grown from 73,832 to 88,168 . Since 1970 , the average vessel size has grown by $43 \%$ from 4,337 gt to 6,201 gt.

Another major feature of world trade is the increasing use of containers for shipping goods. The volume of world trade has grown at a rate greater than that of gross output due to increasing globalization manifested in the movements of high-value goods in process of manufacture between countries. This has had a major impact not only on vessel types, but on the requirements within ports and intermodal transport. Container port throughput increased by 300\% since 1985, to an expected 200 million TEUs (twenty foot equivalent units) in 1999. Three independent forecasts all expect this to increase by a further $50 \%$ to about 300 million TEUs by 2005 and one forecast ${ }^{1}$ a doubling by 2010 (ISL, 1999).

Larger ships are being used to move cargoes of containers between regions (intra-regional trading), the cargo often being split for onwards transit by smaller vessels within the region. This integration of regional markets has become a global trend and has boosted the fortunes of the leading regional ports able to handle large vessels efficiently. Examples include Singapore and Rotterdam.

For high-cost manufacturing regions such as Western Europe it has been increasingly necessary for the marine industries to focus on high-tech / highvalue / low-volume situations. One example of this is a concentration on the special vessels sector of shipbuilding, for example cruise vessels and offshore.

Numbers and size of cruise vessels remained fairly constant throughout the 1980s, but the 1990s have seen dramatic growth. Numbers have grown from 170 in $1990(1,000$ gt or greater) to 235 in 1999. In 1990, there were just three 'super ships', vessels greater than 70,000 tons, in 1999 there were 29 , accounting for $31 \%$ of vessels. In 1990 there were a total of 114,000 passenger berths, in 1999 berths for 204,000. This market sector has been suffering from a shortage of suitable yard capacity for newbuilds.

Offshore vessels form another special fleet totaling 3,394 ships. ${ }^{2}$ The greatest number of these are anchor handling tugs/supply vessels which form $67 \%$ of the world fleet. During the past decade, the greatest growth was in 1998/99. This was, we believe, due to the requirements of the booming deepwater oil \& gas sector. A major downturn in orders resulted from the oil price fall of 1998 but growth is expected from 2001. It is of note that during the last surge in orders the greatest share went to Norway, particularly of the higher value vessels.

Experienced, well-qualified personnel are key to the future prosperity of the global marine industries. The past few years have seen an ongoing shift in the age profile of employees in western world marine

\footnotetext{
1 ISL Shipping Statistics Yearbook 1999, ISL, Hamburg

2 The Offshore Vessel Register, Clarkson, London
} 
industries. This is coupled with difficulties in recruitment of high-ability new entrants due to competition from high-tech industries, the difficulties of retention, due in many instances to the absence of a career structure and the problems of working in what at times are highly cyclical industries with few employment guarantees, and in some cases the antisocial working hours. These issues are not helped by the negative public perceptions of certain large marine industries, particularly offshore oil \& gas and perhaps shipbuilding. There have been some efforts by organizations to change these perceptions, but a wider approach is necessary for the marine industries as a whole.

In common with other industries, the marine industries are undergoing fundamental changes in their approach to business. There is a global trend to improve efficiency by minimizing the number of suppliers that companies have to deal with. This is manifesting itself in one-stop shopping for major units of equipment and services with more and more previously separate items ordered via a single source supplier as integrated packages.

At a lower level, there is a growth in the supply of integrated systems by main contractors. In shipbuilding for example, the trend is towards integrated bridge systems (IBS) and integrated propulsion systems (engine, gearbox, shaft, bearings, seals and propeller). This integration potential becomes even greater with electrically propelled ships. But increasing integration brings some problems:

- The process favors larger suppliers, producing great difficulties for small companies

- The main contractor for a 'package' acts as the client for the small sub-contractors effectively blocking the lines of communication between supplier and end user client.

- The end-user no longer carries out $R \& D$ as this is required for 'products' now supplied by the main contractor who, not being a 'products' supplier, does not see R\&D as its role.

As projects grow in size, the ability to provide long-term project finance becomes of increasing importance. In many instances this is the crucial factor in winning a project and is particularly significant in countries such as Japan where there are strong links between the finance houses and manufacturing sector and in some instances government-owned export banks. Financing may be at the overall project level or key component, for example it is usual for major engine manufacturers to have their own finance companies. It has long been the case in some countries that in order to win business a shipbuilder may take direct equity participation in a new ship.

Globalization is a major trend and shipbuilding was one of the leaders of this process. Our surveys of many marine industry sectors show that in general the customer does not care where a product is produced as long as price, delivery and quality meet its requirements. The only 'local' concern is for good communication, with the result that many major corporations are adopting the theme of "work global act local". So in common with other industries, manufacturing of marine products is being re-located to areas of low cost production. As a second stage of this process, computer software writing, previously thought of as being a domain of the 'developed world' is increasingly being switched to low-cost locations with well qualified personnel such as India and Russia.

Clustering of marine business in specific locations can provide a balance to the globalization of manufacturing. In the UK, cases in point include the offshore oil industry cluster in Aberdeen, and the marine services industry in London and in the U.S., the naval cluster around San Diego.

Technical advances are addressing a number of common problems and solutions across the various marine sectors. To give one example, as in the aircraft industry, all-electric systems are increasingly being considered as a preferred alternative to hydraulics for both control and actuation. Electrical systems offer advantages such as power conversion efficiency, transmission efficiency and response times. Specific examples include the concept of the all-electric ship. Oil industry subsea control systems are presently electrohydraulic, though using electronic data transmission. Power is delivered electrically so the development of electrical valve actuators is presently underway.

Remotely operated underwater vehicles (ROVs) are generally powered by an on-vehicle electrohydraulic system. In very deep waters however, long cable lengths result in very low conversion efficiencies. New electrical vehicles are under development but again the key technology is electrical actuators.

Electrical propulsion is already established in a number of vessel types and is of great interest for naval operations where vessels require stealth and spend most of the time running at less than $50 \%$ power. There are also commercial implications as electrical propulsion breaks the dominant position of the few engine supply companies who seek to deliver complete packages from bridge control to engine, gearbox, shaft and propeller.

Marine electronics has become an important sector as the electronics content of vessels grows with increasing use of vessel automation \& control systems and the integrated bridge. This trend is due to reductions in vessel manning, safety requirements and the advent of the electronic chart. A number of large corporate groupings are developing worldwide. When combined with the moves into electric propulsion, even larger singlecompany content is possible.

Underwater electronics is a specialist sector, its customers are the ocean science, ocean survey and underwater contracting communities and sectors such as offshore oil where great use is made of instrumentation 
and sensors ranging from sonar to TV cameras. The growth of the client industries such as offshore oil industry and submarine telecoms has resulted in continuing development of the sector and an increasing demand for its products. However, each sub-sector of underwater electronics (such as underwater TV) has a limited market with the result that a specific characteristic of the business is the predominance of small companies. Each tends to be fiercely independent with the result that there is little development of wide-capability companies by organic growth.

Information technology: the marine sector can be regarded as three years behind general industry in its level of IT technological development and take-up. Only now with ever-growing competitive pressures is there a concerted drive to increase the use of IT with standard PC's. Use of standard PC hardware is now common on newbuilds and increasingly so on the existing commercial fleet. The development cycle has now moved to the applications that control the increased flow of information from embedded electronics and management systems. The next three years are likely to see a closer integration of both the embedded vessel systems, standard PC architecture and applications, particularly those that supply information to the onshore office to reduce operational costs (e.g. crew \& vessel information) and those that supply extra information to the crew to improve efficiency (e.g. updated charts, weather etc).

Leisure expenditure has grown worldwide with the increase in personal wealth. In addition to growth in the cruise industry and leisure boating, scuba diving has developed into a major activity. In the case of the UK's ship and boat exports, leisure boats such as yachts at $£ 235$ million have a value similar to that of offshore oil industry systems (floating and

Ocean research has grown significantly in response to developing concerns platforms) and 15 times that of conventional commercial ships.

Environmental impact: all industries have environmental impact and individual marine industries vary greatly in this respect. Concerns have been raised relating to aggregates extraction, aquaculture, fishing, offshore oil \& gas, etc. However, the negative public perceptions of some industries are out of all proportion to the measured effects-the deepwater activity of the offshore oil \& gas industry is a case in point.

Ocean research has grown significantly in response to developing concerns over the role of the oceans in climate control and the impact of environmental pressure groups. As more industries operate offshore there has been a growth in the demand for metocean data. Naval expenditure on bluewater oceanographic data grew with the cold-war importance of submarine operations. The ending of the cold-war resulted in increased interest in littoral waters.

Where will the jobs be? Increasing globalization driven by the reducing costs of communications, is posing some interesting challenges. For example, why run an R\&D facility in California when individuals with similar qualifications can be hired at one quarter of the price in India or Russia. As activity becomes increasingly globalized the major issue for the future is the location from where a multi-national company chooses to service a third country. Increasingly, issues of nationality of ownership are of less importance than the fundamentals of where jobs are created and to where economic benefit is ultimately delivered.

\section{Table 2}

\section{Offshore oil \& gas macro trends}

- Shallow water fields are depleting

- Deepwater discoveries are growing

- Costs are reducing - improving technology Fast track developments - $50 \%$ reduction in 3 years

- Subsea fields - well numbers to double in 5 years

- Growing use of floating production

- Slow response to oil price recovery

- A major upturn in prospect as oil \& gas prices firm

- But - will the industry have the resources?

- A major manpower problem is building

Figure 2. The World Deepwater Market

source: The World Deepwater Report (DWI)

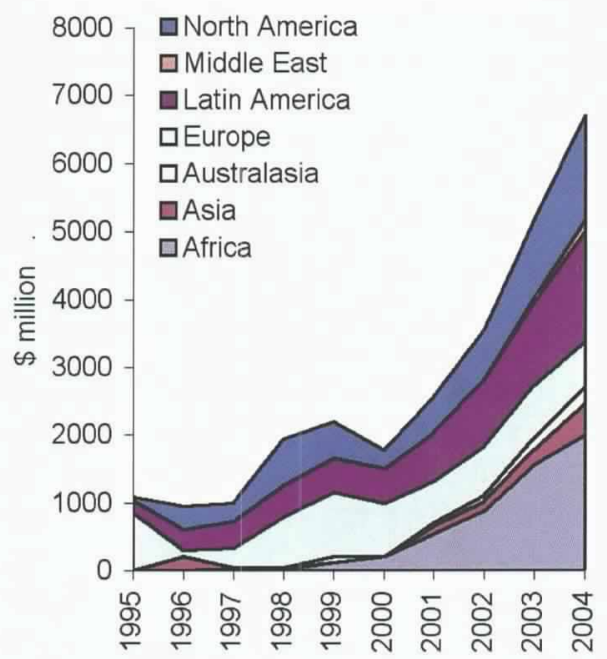




\section{Offshore Oil \& Gas}

Over 4,500 fields have been bought into production to date and at present a further 1,500 are in prospect. The great majority have been located in the U.S. Gulf of Mexico but many have been small developments which are now depleting rapidly. (Table 2).

The growth of offshore Europe was characterized by large fields but these are also depleting and future field prospects, though numerous, will have small reserves. The new field prospects (typically 40,000 barrels per day) are now one tenth of the size of the original North Sea giants. Future growth in large fields will be mainly in deep waters and located in regions such as West Africa and Asia Pacific. (Figure 2).

In May 2000, Sir John Brown of BP Amoco stated, "Of the extra oil \& gas required by 2010, at least a quarter will come from offshore fields, with a high proportion in deep water." At the same time Shell stated that," $22 \%$ of our E\&P budget is targeted at deep water."

Up to 1960 , the maximum water depth from which oil and gas was produced was 60 metres; by 1990, this had passed the $600 \mathrm{~m}$ mark and by 2004 we expect $2,156 \mathrm{~m}$ to be achieved. This is the leading edge of technological achievement in an industry where the mean water depths of offshore fields are currently little more than $100 \mathrm{~m}$.

The World Deepwater Report shows that nearly 20\% of offshore reserves are in depths greater than 300 meters. In total, 173 known development prospects are in water depths greater than $300 \mathrm{~m}$. We forecast that the deepwater market will more than double in size over the next 5 years.

\section{World Naval Expenditure}

Since 1989 (the end of the Cold War), world defense expenditure has fallen by $34 \%$. There are now signs that defense expenditure is beginning to rise, especially naval expenditure with growth in the construction of new naval vessels during the first decade of this century.

The following table (Table 3) shows the number of surface naval vessels in the major navies of the world in 1998. Blue-water vessels are the ocean going fleet: brown-water vessels are generally smaller vessels with a restricted area of operation. The numbers of vessels indicate the market potential for any product or service that is generally adopted by the world's navies.

Naval defense is a very large and diverse area of expenditure. Naval budgets can be up to $30 \%$ of a country's defense expenditure. However, many governments do not separately report naval expenditure. It is difficult to segment defense expenditure into strict categories as problems occur in the definition of what constitutes a naval item in a defense budget.

For the purposes of this paper, the analysis will concentrate on naval vessels and matters relating to vessel construction.

The U.S. provides a lot of detail about its naval

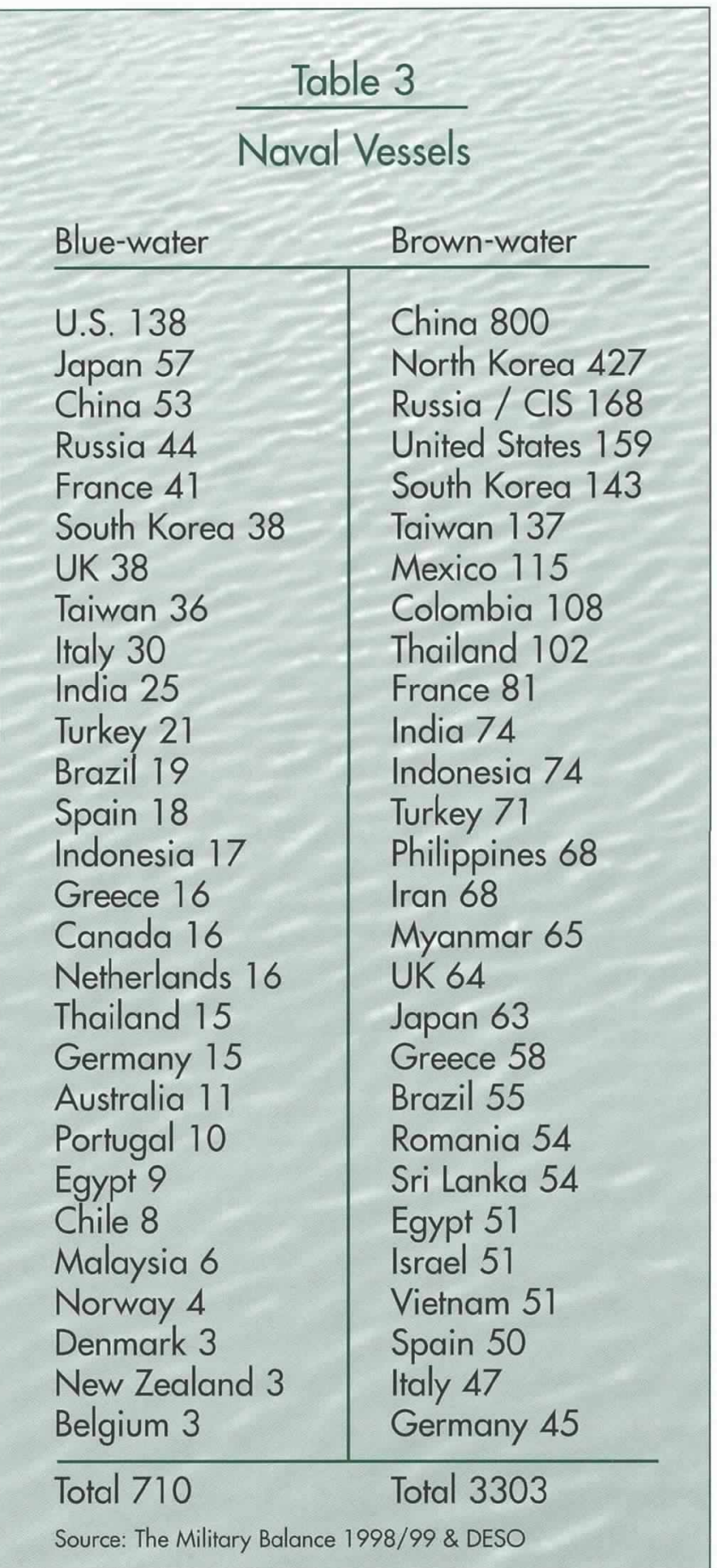

activities and an attempt to infer world naval budgets may be made from U.S. data. The U.S. Navy has approximately $19 \%$ of the world's fleet of blue-water vessels. Given the greater average size, higher specification and value of these vessels and higher personnel costs than elsewhere in the world, a figure for global naval expenditure can be estimated by grossing up values from the U.S. naval budget. This $\$ 83$ billion is probably $30-40 \%$ of the total world naval budget. This suggests a world figure of about $\$ 225$ billion per annum. This figure would include all personnel, equipment and armaments costs as well as submarines. 


\begin{tabular}{|l|rrrrr|}
\hline \multicolumn{5}{|c|}{ Table 4 } \\
\cline { 2 - 5 } U.S. Navy ocean oriented procurement \\
\hline \$ million & 1998 & 1999 & 2000 & 2001 \\
Anti-sub. Warfare & 485 & 540 & 774 & 668 \\
Sub.Warfare & 444 & 654 & 721 & 495 \\
Mine Warfare & 66 & 72 & 89 & 71 \\
Torpedoes & 93 & 90 & 120 & 107 \\
Oceanog./Met & 18 & 29 & 32 & 31 \\
Shipbuilding & 8476 & 6264 & 6829 & 12100 \\
General & 1001 & 1340 & 1488 & 1174 \\
\hline Totals & 10583 & 8990 & 10053 & 14646 \\
Source: U.S. DoD (Y2000 dollars) & & & & \\
\end{tabular}

The U.S. defense budget, which is by far the largest in the world, is beginning to rise and within this budget the Navy is to maintain a $31 \%$ share at least to 2001 (Table 4). With the rise in naval expenditure, procurement rises by $28 \%$ from 1999 to 2001 . Within the procurement budget, shipbuilding is expected to double in 2001 from 1999 and 2000 levels. The U.S. is expected to fund 47 new ships from 2000 to 2005 together with 28 refits.

We estimate world naval expenditure at $\$ 225$ billion per annum to include all personnel, equipment and armaments costs.

\begin{tabular}{|llllll|}
\hline \multicolumn{5}{|c|}{ Table 5 } \\
\cline { 2 - 5 } Merchant fleet ownership \\
Mill dwt & 1995 & 1996 & 1998 & 1999 & 2000 \\
Greece & 113.1 & 118.3 & 121.3 & 127.3 & 131.7 \\
Japan & 85.6 & 87.3 & 89.0 & 93.8 & 95.2 \\
Norway & 47.0 & 48.0 & 52.0 & 52.2 & 53.6 \\
U.S. & 49.1 & 47.8 & 42.8 & 43.6 & 46.4 \\
China & 33.7 & 34.2 & 37.3 & 36.2 & 38.4 \\
Hong Kong & 29.4 & 31.0 & 33.6 & 31.7 & 31.1 \\
UK & 20.8 & 21.0 & 21.2 & 19.2 & 17.5 \\
Germany & 16.0 & 17.0 & 21.2 & 26.1 & 29.2 \\
S Korea & 19.2 & 20.5 & 24.7 & 25.6 & 25.0 \\
Sweden & 11.8 & 13.0 & 16.3 & 21.1 & 18.0 \\
UK & 20.8 & 21.0 & 21.2 & 19.2 & 17.5 \\
Taiwan & 12.2 & 14.3 & 15.2 & 17.6 & 20.0 \\
Singapore & 10.3 & 12.5 & 14.0 & 17.8 & 18.4 \\
Source: Ist, vessels $>1,000$ dwt & & & & & \\
\hline
\end{tabular}

\section{Commercial Shipping}

Shipping is by its very nature an international business and the world fleet of 88,168 merchant vessels of greater than $100 \mathrm{gt}$ is spread throughout the continents. However, the core inter-continental merchant fleet of large vessels $(1,000 \mathrm{gt}+)$ is owned and operated by a relatively small number of maritime nations with just 12 representing over $62 \%$ of the entire large vessel fleet (Table 5).

The shipping industry carries over $98 \%$ by volume of all international cargo. Over five billion tons of cargo was moved in 1997, 45\% liquid (mainly oil, petroleum products and chemicals), 23\% dry bulk (coal, iron ore, grain and phosphate) and 32\% general cargo (including container).

After slow growth in the mid-1990's the past five years has seen an $11.25 \%$ net increase in total vessel tonnage with the main maritime nations increasing their merchant fleets in-line with the growth in world trade. Throughout the past three decades Greece has controlled the largest fleet by tonnage with shipping representing nearly $40 \%$ of its export earnings and over $14 \%$ of GDP. ${ }^{3}$

The growth in shipping revenues is directly correlated to growth in world trade and the World Bank estimate that maritime freight in 1995 was equal to $5.3 \%$ of world import values although in some regions the percentage is higher, notably Africa at $11.4 \%$. Increases in vessel size and efficiency and continuing containerization has seen the cost to the developed world of maritime freight fall from $10.4 \%$ to $8.3 \%$. Estimates from the IMF through to 2005 suggest that world trade will continue to grow on the back of world economic growth and with it maritime freight.

\section{Boating \& Pleasure Craft}

We value the world leisure boating industry at $\$ 38$ billion (a similar size to commercial shipbuilding) and annual world production of pleasure craft is estimated as about 800,000 units. Future prospects for this sector depend on general economic prosperity and its growth is expected to continue at a rate greater than overall economic growth. Given that this sector responds to increases in personal disposable income and together with a general aging of the population in the developed countries of the world, future growth looks likely. It is possible that an annual growth rate of $2-2.5 \%$ in real terms is likely in the medium term.

The number of boats used for leisure activities is estimated as consisting of 34,000,000 craft in 1998 of which North America and Europe have about $80 \%{ }^{4}$ Within Europe the UK has the largest number (1.6 million) with Sweden and France also having over one million. The countries where pleasure boating is the most popular as judged by the number of boats per

\footnotetext{
${ }^{3}$ Greek Ministry of Finance

${ }^{4}$ UCINA Report -The boating industry in the world 1996, 1999
} 
Figure 3. 1999 global shipbuilding by share of value Source: Douglas-Westwood Associates

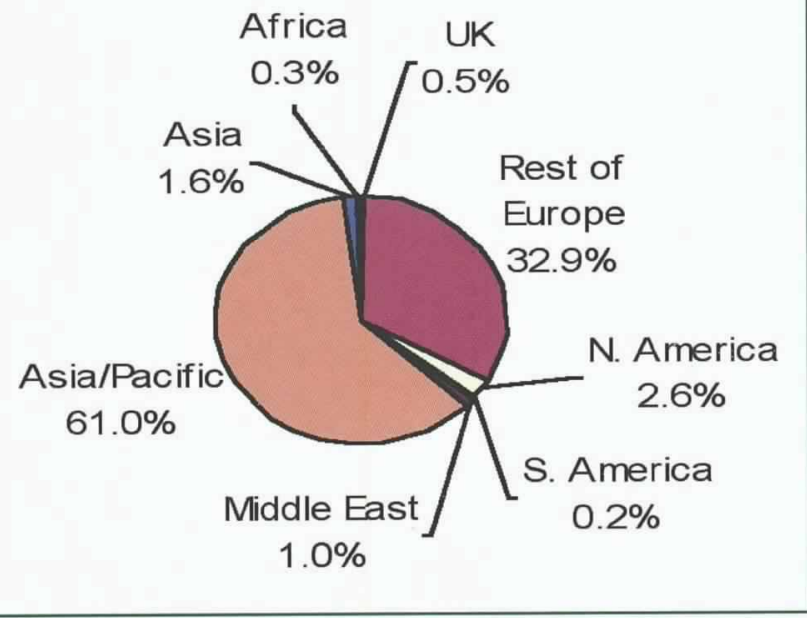

head of population are New Zealand, the U.S. and Australia. Within Europe, Scandinavian countries have great enthusiasm for boating. Norway has 162 boats per 1000 population, Sweden 162 and Finland 135. Modest changes in this boat population took place from 1995 to 1998 with growth in the UK, Japan and U.S..

\section{Shipbuilding}

The main factor impacting on the demand for new ships and hence the global shipbuilding industry is the global level of trading activity which determines the amount of goods transported by sea. In recent years, the number of ships built of a size greater than 100 gross tons have ranged from 2,076 in 1996, reducing to 1,555 in 1999, mainly as a result of the delayed impact of the Asian economic crisis and the associated oil price fall. We expect the total number of vessel deliveries to recover from 2000 onwards then remain fairly stable. But in value terms, the recovery will be in 2002.

Gross tonnage output is expected to remain relatively stable at the 26.5 to 27.5 million ton level from 2000 to 2004. Global shipbuilding is dominated by the yards of the Asia Pacific region, which are responsible for over $80 \%$ of the tonnage built (Figure 3).

$92 \%$ of the gross tonnage we forecast is in the form of cargo carriers that are mainly built by shipyards in the Asia Pacific region. The next largest category is passenger (cruise) ships accounting for about 3\% of tonnage. Gross tonnage does not adequately account for the cost variations of different vessel types. On a price per ton basis, the so-called "special vessel" types (such as offshore production vessels and cruise vessels) are the most expensive.

The shipbuilding market is dominated by the yards of Japan and S.E. Asia, a dominance built up over the post-second world war years, originally based on a combination of low labor costs, subsidies and investment in state-of-the art facilities. These yards are par- ticularly suited to producing multiple vessels of the same type, so called 'production line shipbuilding', and they have captured the largest sector, dry cargo vessels and tankers. The rest of the world has virtually withdrawn from this sector.

The largest share of shipbuilding by value, some $63 \%$, is taken by the Asia Pacific region, but it of interest to note that this is followed by Europe at 33\%. Much of the present shipbuilding success of several European countries is associated with their long-standing national commitment to the industry manifesting itself in a number of ways.

Where vessels are controlled is also an important factor. Considering larger ships of more that $1,000 \mathrm{gt}$, they total 630 million dwt. $68 \%$ of this tonnage is controlled by just 10 nations, led by Greece and Japan, but with Norway in third place. (Again showing the success of Norwegian policy towards its shipping industry.) The UK controls some 19 million $\mathrm{dwt}$, about 3\% although a small percentage, this is several times its annual share of shipbuilding.

The difference between yard and owner location (discussed earlier) has considerable implications to business sectors such as fleet management and marine equipment sales.

\section{Other Sectors}

The sectors we have discussed so far are just the five largest. Our study for the UK Foresight Marine Panel discusses a further eighteen. Of particular relevance to this journal are underwater vehicles and the whole area of marine research \& development:

\section{Underwater Vehicles}

Over 3,000 ROVs have been built to date by some 75 manufacturers worldwide and the most economical-

Figure 4. Underwater vehicles sales forecasts Source: The World UUV Report (DWL)

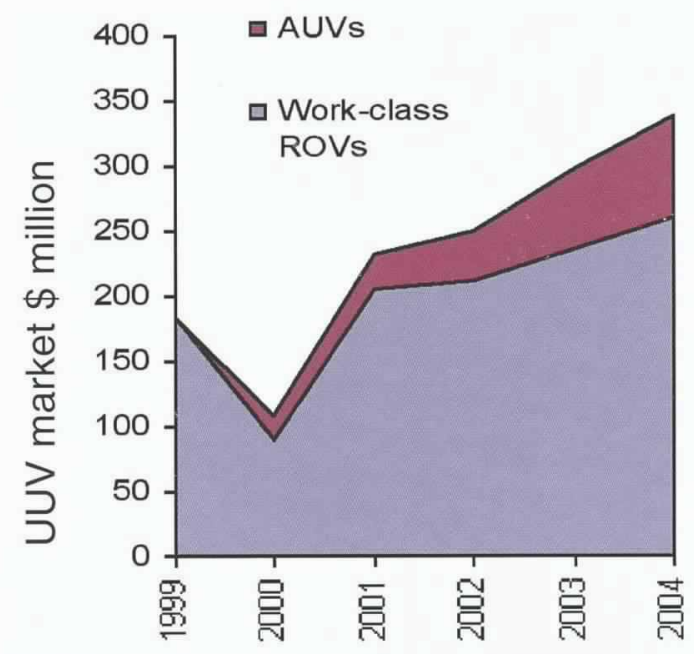


ly important are the 'Work-Class' ROVs with some 478 in operation worldwide (Figure 4). Autonomous underwater vehicles (AUVs) freed of the constraints of an umbilical cable are true robots designed to carry out specific pre-programmed tasks without any communication with the surface. Early units have performed remarkable feats, including a $320 \mathrm{~km}$ under-ice transit whilst laying fiber-optic cable, others completing high precision seabed surveys and cable inspections.

Work-Class ROVs: in 1999, 61 units were delivered at an estimated value of $\$ 183$ million. We expect deliveries to have declined substantially in 2000, mainly due to the delayed effects of the earlier oil price fall. Considering the next 5 years, our base-case gives a growth in the market of $49 \%$ resulting in deliveries totaling $\$ 1$ billion.

AUVs: over the period 2000 to 2004 we believe that there are prospects for deliveries of 92 AUVs giving a market of $\$ 78 \mathrm{~m}$ in 2004 . At first sight it seems very unlikely, however to put this into context, various attempts to determine numbers of AUVs produced to date have identified from 50 to 77 units. Primary factors that potentially reduce the cost-saving potential of the AUV are the costs of the vehicle itself and those of the support vessel. If AUVs require very high specification / high cost support vessels, then this could remove some of the potential market.

\section{Research \& Development}

It is difficult to describe $R \& D$ as a separate sector as $R \& D$ expenditure occurs in all the marine sectors discussed earlier. Defense research and industrial research form the largest sectors, but in both cases it is difficult to derive estimates; defense due to security reasons and industrial due to the very large numbers of companies involved across the marine industries.

Figure 5. The $\$ 19 \mathrm{Bn}$ global marine R\&D market

Source: Douglas-Westwood Associates

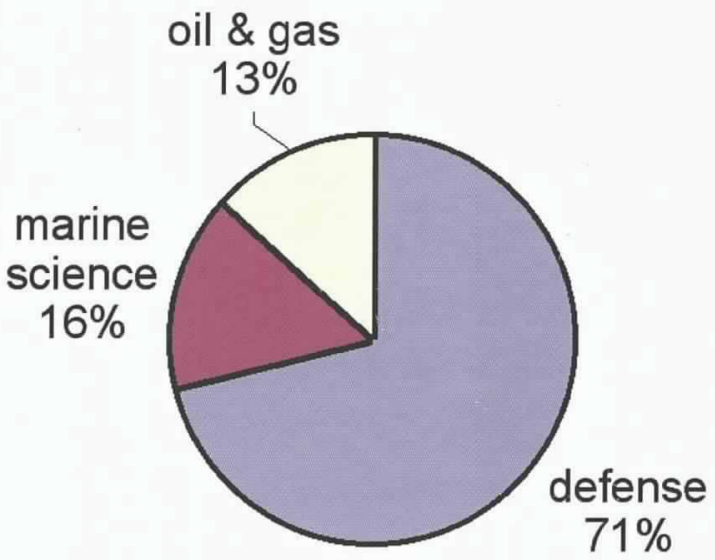

To the many organizations that target government and industrial research funding, $R \& D$ is a multi-billion dollar 'market' in its own right (Figure 5).

Industrial research expenditure is subject to the fortunes of particular marine sectors-for example the recent oil-price down cycle resulted in a massive cutback in R\&D expenditure by offshore oil \& gas companies and served to reinforce the view that the greatest value for money could be obtained by 'gearing' their R\&D funding by investment in joint industry programs that address common problems.

Public and private investment in oceanographic research is estimated to be up to $\$ 3$ billion per annum. The U.S. and Japan spend the greatest amount followed by the UK and France, each having expenditure for all aspects of oceanographic research of about $\$ 300$ million each. ${ }^{5}$ The research areas included in this estimate of expenditure include global climatology, oceanography, and marine technology. The agencies that spend the greatest amounts are the U.S. NOAA and Japan's JAMSTEC. NOAA's total budget for FY 2000 was over \$ 2.5 billion of which $\$ 280$ million can be attributed to "oceanic and atmospheric research". NOAA is also spending \$213 million on "Recovering Protected Species", and \$426 million on "Building Sustainable Fisheries".

The largest research 'market' is the U.S. where we can identify 159 organizations (mainly universities) who operate 100 research vessels, but many of these are small boats.

The total U.S. Navy 2000 budget for 'RDTE' is stated as $\$ 8$ billion. It is however difficult to determine the value of naval R\&D expenditure as much of the necessary information is not in the public domain, also there are complications in segmenting cross-service programs.

\section{Conclusions-Growth Prospects}

Our detailed views on growth prospects can be found in the publication UK Marine Industries-World Export Market Potential. In summary, our analysis shows that the marine industries' growth over next five years could total $\$ 51$ billion, the largest being in the sectors of:

- marine transportation,

- the ports industries,

- the leisure industries including leisure boating and the cruise business,

- offshore oil \& gas industry,

- marine services in its many aspects,

- submarine cables,

- minerals (specifically offshore diamonds),

- marine biotechnology,

- underwater vehicles,

- marine IT (but from a small base), and

- renewable energy (from an even smaller base).

\footnotetext{
${ }^{5}$ Donneés économiques maritimes françaises - Ifremer 1999
} 
In other sectors, growth will also occur, but in specific aspects of the industry. For example, naval expenditure is changing from blue-water to coastal, from personnel to hardware and systems. The value of shipbuilding, marine equipment, ship repair and conversion, may remain broadly similar, but expenditure will change across vessel types and equipment.

We expect the strongest growth to occur in the three main regions of Asia, Europe and North America, and significant growth in Africa-mainly from offshore oil expenditure, and in South America-in shipping and port development. 사

\section{Acknowledgements}

The authors wish to express their thanks to the individuals who have contributed to the studies on which this paper is based. Particular thanks are due to Foresight Marine Panel who gave permission for us to use extracts from UK Marine Industries-World Export Market Potential.

\section{Main information sources}

UK Marine Industries-World Export Market Potential by Douglas-Westwood Associates. Published by the Institute of Marine Engineers, 2000. ISBN: 1-902536-38$X$. A summary can be found on www.dw-1.com, together with information and papers based on the following studies:

"The Offshore Europe Report"

"The World UUV Report"

"The World Deepwater Report"

Douglas-Westwood Associates

Whitebeams, Pett Bottom, Canterbury, CT4 6EH, UK

Tel: +44 1227831879

Fax: +44 1227832092

Email: admin@dw-1.com

Web site: www.dw-1.com

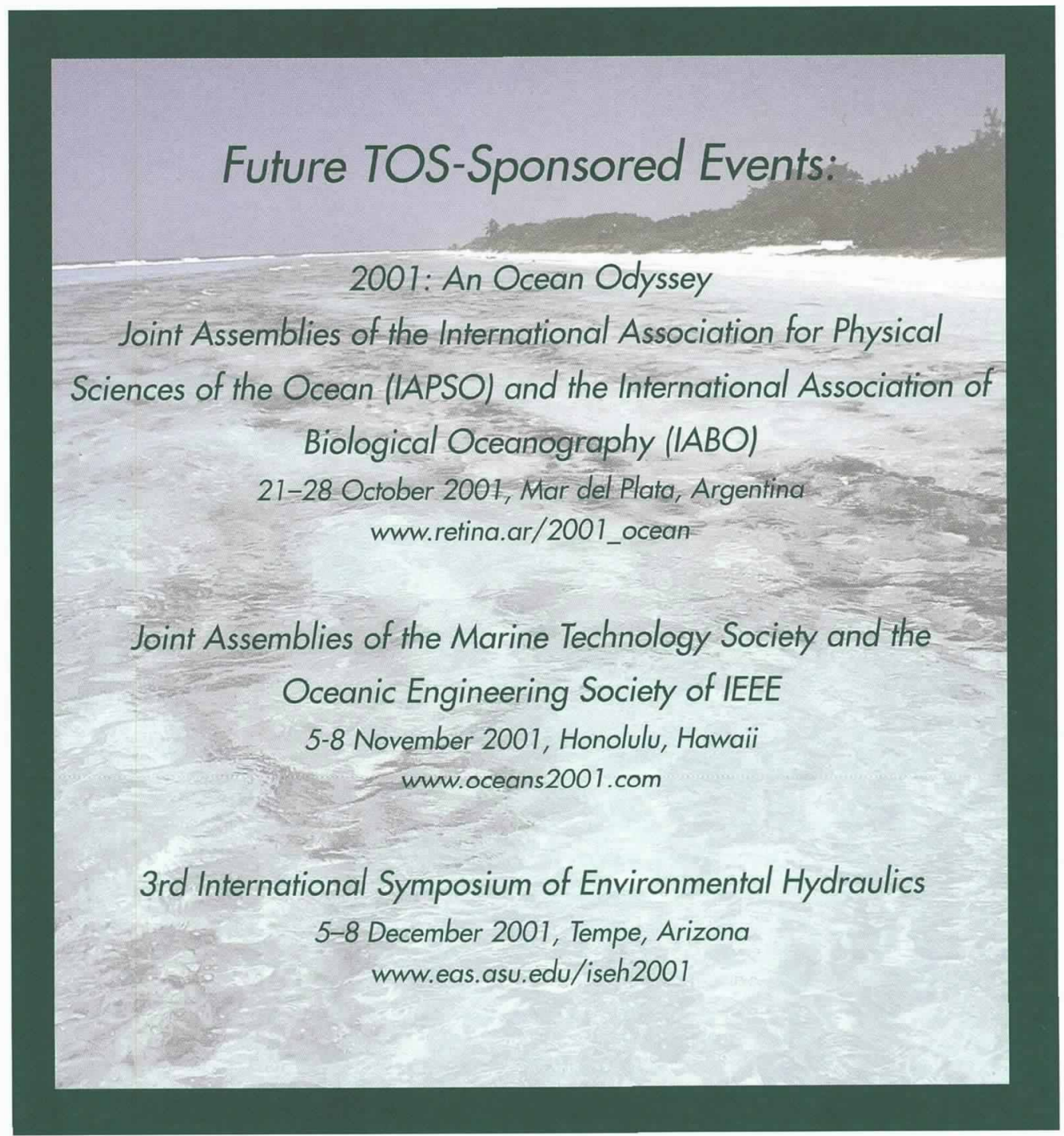

